\title{
Characteristics of dissolved organic matter in the rhizosphere of light-irradiated Arabidopsis thaliana during phytoextraction
}

\author{
Hong $\mathrm{Niu}^{1}$, Dan Chen ${ }^{2}$, Tian $\mathrm{Gan}^{3}$, Jiawei $\mathrm{Wang}^{2}, \mathrm{Min} \mathrm{Cao}^{4}$, and Jie $\mathrm{Luo}^{2}$ \\ ${ }^{1}$ South-Central University for Nationalities \\ ${ }^{2}$ Yangtze University \\ ${ }^{3}$ Shandong University \\ ${ }^{4}$ University of Leicester
}

September 30, 2021

\begin{abstract}
Light, one of the most important natural resources for plant species, significantly influences the biomass yield and nutrient uptake capacity in plants. However, the impacts of light treatment on the toxicity of metals in soils has rarely been reported. Light irradiation treatments were performed to evaluate the influence of red, yellow, and blue lights on the concentrations and fractions of dissolved organic matter (DOM) in the rhizosphere soils of Arabidopsis thaliana. The results showed that monochromatic red light significantly raised the levels of DOM and proportions of hydrophilic fractionations in the rhizosphere of A. thaliana relative to the control, while monochromatic blue light had the opposite effect. Moreover, the proportions of hydrophobic acid, which can mobilize Cd effectively, also raised with increasing doses of red light, which stimulated Cd mobilization. The application of yellow light not only increased the levels of hydrophobic acid in monochromatic red light treatment, but also decreased the proportion of hydrophobic fractions in monochromatic blue light treatment, partially weakening the negative impacts of pure blue light on soil Cd activation. Moreover, DOM from the combined red, yellow, and blue lights resulted in a significantly stronger Cd extraction efficiency compared with the other light irradiation treatments, consequently enhancing the Cd phytoextraction efficiency of A. thaliana. The findings of this study demonstrated that a suitable light combination can enhance the phytoremediation effect of A. thaliana by activating soil Cd, and this method can be extrapolated to the real field, where light irradiation can be easily applied.
\end{abstract}

\section{Hosted file}

Graphical abstract.pdf available at https://authorea.com/users/438638/articles/539781characteristics-of-dissolved-organic-matter-in-the-rhizosphere-of-light-irradiatedarabidopsis-thaliana-during-phytoextraction

\section{Hosted file}

highlight.docx available at https://authorea.com/users/438638/articles/539781characteristics-of-dissolved-organic-matter-in-the-rhizosphere-of-light-irradiatedarabidopsis-thaliana-during-phytoextraction

\section{Hosted file}

manuscript.docx available at https://authorea.com/users/438638/articles/539781-
characteristics-of-dissolved-organic-matter-in-the-rhizosphere-of-light-irradiated-
arabidopsis-thaliana-during-phytoextraction

\section{Hosted file}


Conflict of Interest.doc available at https://authorea.com/users/438638/articles/539781characteristics-of-dissolved-organic-matter-in-the-rhizosphere-of-light-irradiatedarabidopsis-thaliana-during-phytoextraction 